
\title{
28 Research Square \\ What is the main problem in conservative management for complicated appendicitis? A systematic review
}

\section{Chi Zhang}

Affiliated Hospital of Medical College Qingdao University https://orcid.org/0000-0002-4220-2212

\section{Xuemeng Ren}

Affiliated Hospital of Medical College Qingdao University

Peng Gao (D 445155875@qq.com )

https://orcid.org/0000-0003-0769-3754

\section{Research article}

Keywords: Appendiceal abscess; Complicated appendicitis; Appendectomy; Conservative management

Posted Date: March 23rd, 2020

DOI: https://doi.org/10.21203/rs.3.rs-17722/v1

License: (c) (i) This work is licensed under a Creative Commons Attribution 4.0 International License.

Read Full License 


\section{Abstract}

Background: As a classification of appendicitis, complicated appendicitis has no standardized treatment for adults.

Method: According to the related literature systematically searched on PubMed, Embase, Cochrane and Web of Science, we evaluated the efficacy of surgical treatment and conservative treatment for complicated appendicitis, especially focused on the outcomes about the length of stay, operation time, postoperative complications and unplanned additional intervention, in the literature.

Result: A total of 14 studies were involved in the meta-analysis, including 845 patients in the immediate operation group (IO) and 756 patients in the conservative management group (CM). Compared with conservative treatment, the total hospitalization time was reduced by 1 day $(\mathrm{WMD}=-1.29,95 \% \mathrm{Cl}[-2.42$, -0.16], $P=0.03<0.05)$. The incidence of unplanned additional intervention in patients undergoing emergency surgery is lower than that of conservative treatment $(\mathrm{OR}=0.18,95 \% \mathrm{Cl}[0.11,0.30], \mathrm{P}<0.00001)$. Surgical patients are more likely to have complications such as wound infection $(\mathrm{OR}=2.41,95 \% \mathrm{Cl}[1.08$, 5.38], $\mathrm{P}=0.03<0.05)$ and intestinal obstruction $(\mathrm{OR}=4.14,95 \% \mathrm{Cl}[2.21,7.75], \mathrm{P}<0.00001)$ than conservative patients. The incidence of abdominal abscess was lower than that of conservative treatment, and the difference was not statistically significant $(\mathrm{OR}=0.9,95 \% \mathrm{Cl}[0.54,1.47], \mathrm{P}=0.66>0.05)$.

Conclusion: Compared with conservative management patients, immediately operated patients have shorter hospitalization time and less unplanned intervention, which can significantly reduce the readmission opportunity of patients with complicated appendicitis and lighten the burden of follow-up and medical resource consumption.

\section{Background}

Appendicitis is the most common form of acute abdomen, affecting about $7-8 \%$ percent of adults ${ }^{1}$. It can be divided into uncomplicated appendicitis and complicated appendicitis, between which complicated appendicitis is often related to the rapid development of acute appendicitis or the improper and untimely treatment ${ }^{2}$, the incidence of which is about 3.8-5.0\% of acute appendicitis ${ }^{1}$. When the appendix appears to exudate, necrosis and perforation, the inflammatory factors spread into the surrounding tissues of the appendix, causing the retina and the nearby small intestine to form an appendiceal wrapping. After successful formation, an inflammatory mass or localized abscess containing pus, small intestine and retina is formed ${ }^{3}$.

For uncomplicated appendicitis, a number of studies have shown that conservative treatment with antibiotics and emergency surgery can achieve relatively good results in the adults ${ }^{4,5}$. But so far, there is still a big controversy on the treatment of complicated appendicitis. Some studies have shown that immediate operation (IO) for complicated appendicitis has the advantages of short hospitalization time and low recurrence rate compared with the early conservative treatment of anti-infection and the interval 
surgical resection ${ }^{6,7}$. At the same time, recently published meta-analyses indicate that the postoperative complications of early surgery were significantly higher than that of conservative surgery 6,8 .

However, most studies have no research on the short-term recurrence after early treatment and abdominal abscess appendicitis. With the improvement of level of antibiotics and medical technology, laparoscopic and percutaneous puncture drainage has gradually become a new operation for complicated appendicitis, and the treatment of complicated appendicitis has changed ${ }^{9,10}$, the cure rate and complication of complicated appendicitis has been changed ${ }^{11}$. The main purpose of this study is to include recent related studies and compare the complicated appendicitis treated by surgical treatment with conservative treatment through meta-analysis.

\section{Methods}

\section{1. literature retrieval}

By the free word and keywords retrieval, free words ('abscess' or 'phlegmon', 'laparoscopic' or 'open appendicectomy' or 'appendectomy', 'conservative' or 'on-surgical treatment' or 'management'), MESH: 'Appendicitis', the related articles were also listed as search results to broaden the research library. EMBASE, PubMed, Web of Science, Ovid, Cochrane and other databases were used to retrieve relevant studies in the past 20 years from 2000 to present. The obtained literature was summarized and the duplicate literature was removed.

\section{Objective research acquisition}

Two researchers (Chi Zhang, Xuemeng Ren) independently filtrate the target studies according to the Cochrane Handbook ${ }^{12}$ and the unified literature standards. The author, year, research purpose, sample size and relevant effect indexes selected for the study were sorted out respectively. The collected data were reviewed and discussed by the study organizer (Peng Gao), and the controversial documents were selected or excluded by the study organizer.

\section{Research selection and exclusion criteria}

Only studies comparing surgical methods (laparoscopic or open) and conservative methods (antiinfection or including early drainage and selective appendectomy) could be included in the analysis.

According to NOS ${ }^{13}$ score, for eligible studies, the scores higher than 6 were defined as high-quality studies. For randomized controlled studies, evidence quality was evaluated using the method recommended by Cochrane Handbook ${ }^{12}$. The selected study should include the following elements $\rrbracket$

- Considering the differences in children's development at different ages ${ }^{14,15}$, only patients with complicated appendicitis over 12 could be selected as the study subjects. 
- Outcome indicators should include at least one kind of hospitalization time, postoperative complications or the total number of complications.

- The intervention and control measures should be surgical (laparoscopic or open surgery) and conservative (antibiotics, drainage or no drainage).

- Describe the surgical treatment and conservative treatment of the treatment process and results in details.

- Report the comparative analysis with other studies or similar studies by the same author.

- Randomized controlled study or retrospective study should be including.

exclusion criteria $\bigotimes$

- The study that does not meet the selection criteria.

- Important outcome data is incomplete, and there is no report on the results of the two treatments.

- The study samples include patients with uncomplicated appendicitis.

- The research cannot obtain the required data for meta-analysis through public channels.

- The study cannot accurately deduce the outcome.

\section{Interested ending and definition}

The immediate operation group (IO) includes patients with complicated appendicitis who underwent emergency surgical treatment and/or exploration. The conservative management group (CM) included patients with complicated appendicitis who failed early conservative treatment, had emergency surgical treatment after early conservative treatment, had elective surgery after early conservative treatment, and did not undergo surgery at all. The outcomes used to contrast the differences between the immediate appendectomy group and the conservative management group were as follows $\rrbracket$

- The length of hospital stay includes the first time of hospital stay, the average length of hospital stay, the length of hospital stay after the operation and the total length of hospital stay with the readmission time.

- The length of antibiotics includes the time of intravenous antibiotics in the first hospitalization and the time of intravenous antibiotics after recurrent appendicitis and other complications.

- Overall complications refer to the number of complications caused by complicated appendicitis during the whole (including follow-up period). Wound infection occurs on the surface or deep layer of the skin after the wound is closed, eliminating the formation of an abscess. Abdominal abscess and ileus obstruction were defined during the whole treatment process diagnosis by imaging diagnosis or emergency surgery or interval appendectomy.

- Unplanned additional intervention refers to the unplanned medical intervention (repeated surgery, emergency surgery, puncture drainage, etc.) for recurrent appendicitis, abdominal abscess, etc. that occurs during the treatment and follow-up period. 


\section{Data analysis and processing}

Statistical analysis was performed using the Revman 5.3 software provided by the Cochrane collaboration and the Stata 15.0. For continuous variables, Weighted Mean Difference (WMD) and Standardized Mean Difference (SMD) were used for analysis to calculate the $95 \%$ confidence interval. For some continuous variables that were difficult to calculate, the formulas of Cochrane Handbook ${ }^{12}, \mathrm{Hozo}^{16} \mathrm{q}$ Luo ${ }^{17}$ and Wan ${ }^{18}$ were used for treatment. Using the odds ratio (OR) as the statistic, to analyze the dichotomous variables in the study. OR $<1$ was beneficial to IO group. OR value was considered to be statistically significant at the level of $P<0.05$. $c^{2}$ test was used for the analysis of inter-study heterogeneity, fixed effect model was used for homogeneous study $₫ \mathrm{P}>0.05,2<50 \% \bigotimes$, and random effect model was used for heterogeneous study $\mathbb{P}<<0.05,2>50 \% \bigotimes$. Stata 15.0 was used to analyze publication bias in heterogeneous studies. By the Egger method, $P<0.1$ was set to analyze the existence of publication bias. The effect of publication bias on the robustness of meta-analysis was evaluated by the metatrim method ${ }^{19}$

\section{Result}

A total of 148 articles were retrieved and 14 studies were eventually included (see Fig. 1 for the procedure of literature selection), of which 845 patients were treated surgically (group IO) and 756 patients were treated conservatively (group CM). A total of 4 randomized controlled studies (RCT) ${ }^{20-23}$ were included, and 10 retrospective studies (RS) ${ }^{24-33}$ were included. The literature information of major concern is shown in the following table (Table 1). 


\section{Tables 1. Characteristics of the Included Studies}

\begin{tabular}{|c|c|c|c|c|c|c|c|c|c|}
\hline \multirow[t]{2}{*}{ Author,year } & \multirow[t]{2}{*}{$\begin{array}{l}\text { Study } \\
\text { type }\end{array}$} & \multicolumn{3}{|c|}{ Case } & \multicolumn{2}{|c|}{$\begin{array}{l}\text { Age (mean } \pm \\
\text { SD) }\end{array}$} & \multirow[t]{2}{*}{$\begin{array}{l}\text { Inclusion } \\
\text { criteria }^{a}\end{array}$} & \multirow[t]{2}{*}{$\begin{array}{l}\text { Matching } \\
\text { criteria }^{b}\end{array}$} & \multirow[t]{2}{*}{ NOS } \\
\hline & & 10 & $\mathrm{CM}$ & IAA & 10 & $\mathrm{CM}$ & & & \\
\hline $\begin{array}{l}\text { Aranda- } \\
\text { Narváez, } \\
2010^{24}\end{array}$ & RS & 15 & 15 & 15 & $\begin{array}{l}35.8 \\
\pm 12\end{array}$ & $\begin{array}{l}35.4 \\
\pm 12\end{array}$ & $1,2,3,5$ & $\begin{array}{l}1,2,6,10 \\
11\end{array}$ & 8 \\
\hline brown, $2003^{25}$ & RS & 36 & 68 & 25 & $\begin{array}{l}30.6 \\
\pm 12.3\end{array}$ & $\begin{array}{l}34.8 \\
\pm 13.5\end{array}$ & $1,2,3,6$ & $\begin{array}{l}1,2,8,10 \\
11,12\end{array}$ & 7 \\
\hline $\begin{array}{l}\text { Deelder, } \\
2014^{26}\end{array}$ & RS & 34 & 85 & $\mathrm{~nm}$ & $\begin{array}{l}41.2 \\
\pm 23.1\end{array}$ & $\begin{array}{l}45.0 \\
\pm 22.1\end{array}$ & $1,2,3,6$ & $\begin{array}{l}12,4,6,7 \\
8,9,10,11 \\
12\end{array}$ & 7 \\
\hline $\begin{array}{l}\text { Demetrashvili, } \\
2019^{27}\end{array}$ & RS & 27 & 47 & 24 & $\begin{array}{l}32.5 \\
\pm 11.7\end{array}$ & $\begin{array}{l}35.2 \\
\pm 12.4\end{array}$ & $\begin{array}{l}1,2,3,5, \\
6\end{array}$ & $\begin{array}{l}1,2,4,5,6 \\
7,8,10,11 \\
12\end{array}$ & 7 \\
\hline khan $S, 2016^{20}$ & RCT & 150 & 150 & 150 & $\begin{array}{l}26.08 \\
\pm 10.6\end{array}$ & $\begin{array}{l}25.89 \\
\pm 9.43\end{array}$ & $1,2,5$ & $1,2,10,11$ & 5 \\
\hline kumar, $2004^{21}$ & $\mathrm{RCT}$ & 20 & 20 & 20 & $\begin{array}{l}31.6 \\
\pm 14.6\end{array}$ & $\begin{array}{l}26.0 \\
\pm 12.4\end{array}$ & $1,2,3,6$ & $\begin{array}{l}1,2,5,10 \\
11\end{array}$ & 6 \\
\hline liu, $2007^{28}$ & RS & 104 & 17 & 17 & $\begin{array}{l}37 \pm \\
10.3\end{array}$ & $\begin{array}{l}41 \pm \\
11.2\end{array}$ & $\begin{array}{l}1,2,3,4 \\
5\end{array}$ & $\begin{array}{l}1,2,5,3,8 \\
10,11,12\end{array}$ & 7 \\
\hline $\begin{array}{l}\text { Mentula, } \\
2015^{22}\end{array}$ & $\mathrm{RCT}$ & 30 & 30 & $\mathrm{~nm}$ & $\begin{array}{l}46.1 \\
\pm 27.1\end{array}$ & $\begin{array}{l}46.5 \\
\pm 27.2\end{array}$ & $1,2,6$ & $\begin{array}{l}1,2,3,4,8 \\
9,10,11\end{array}$ & 7 \\
\hline Motie, $2016^{29}$ & RS & 24 & 49 & 25 & $\begin{array}{l}36.0 \\
\pm 15.5\end{array}$ & $\begin{array}{l}43.2 \\
\pm 19.3\end{array}$ & $1,2,3,6$ & $\begin{array}{l}1,2,8,10 \\
11,12\end{array}$ & 6 \\
\hline Oliak, $2001^{30}$ & RS & 67 & 88 & 52 & $\begin{array}{l}31 \pm \\
10\end{array}$ & $\begin{array}{l}35 \pm \\
15\end{array}$ & $1,2,5,6$ & $\begin{array}{l}1,2,4,8,9 \\
7,10,11,12\end{array}$ & 8 \\
\hline $\begin{array}{l}\text { Pathan, } \\
2018^{23}\end{array}$ & RCT & 50 & 50 & 50 & $21.5 \pm 11$ & & $1,2,3,5$ & $\begin{array}{l}1,2,3,8,10 \\
11,12\end{array}$ & 5 \\
\hline $\begin{array}{l}\text { Shekarriz, } \\
2019^{31}\end{array}$ & RS & 195 & 53 & 41 & $\begin{array}{l}53.55 \\
\pm 21.8\end{array}$ & $\begin{array}{l}56.02 \\
\pm \\
19.65\end{array}$ & $1,2,6$ & $\begin{array}{l}1,2,3,6,8 \\
9,10,11\end{array}$ & 8 \\
\hline $\begin{array}{l}\text { Watanabe, } \\
2019^{32}\end{array}$ & RS & 33 & 49 & 49 & $\begin{array}{l}43.8 \\
\pm \\
19.25\end{array}$ & $\begin{array}{l}39 \pm \\
14.75\end{array}$ & $1,2,5,6$ & $\begin{array}{l}1,2,8,9,10 \\
11\end{array}$ & 7 \\
\hline Young, $2018^{33}$ & RS & 60 & 35 & 14 & $\begin{array}{l}51 \pm \\
19.6\end{array}$ & $\begin{array}{l}50.9 \\
\pm 19.4\end{array}$ & $\begin{array}{l}1,2,4,5 \\
6\end{array}$ & $\begin{array}{l}1,2,3,4,5 \\
10,11\end{array}$ & 8 \\
\hline
\end{tabular}




\section{Tables 1. Characteristics of the Included Studies}

a: Inclusion criteria: 1 . male\& female; 2 . adult patients; 3 . clinical symptoms; 4 . perforated appendix; 5. appendiceal mass; 6 . appendiceal abscess;

b: Matching criteria:1. gender; 2 . age; 3 . BMl; 4 . duration of symptoms; 5 . operate time; 6 . ASA; 7. heart rate; 8 .white cell count; 9 . CRP; 10 . complication; 11 . hospital stay; 12 .temperature.

IO: immediate operation; CM: conservative management; IAA: interval appendectomy; RS:

retrospective study; RCT: randomized controlled trial; NOS: Newcastle-Ottawa scale;Nm: not

mentioned 


\section{Tables 2. Outcomes of Interest}

Outcomes of Interest (study number)

overall hospital-stay [20-26, 28-33]

Post operate stay [26, 28, 32, 33]

Operate time $[27,28,32,33]$

Overall complication $[28,30]$

Whole complication of post operates

$[21,27,29,31,32]$

Wound infections

wound infections $[20,21,23,24-32]$

wound infections with percutaneous 4

drainage $[25-27,30]$

Abdominal abscess $[20,22,23,26-\quad 10$

32]

Bowel obstruction [25, 26, 29-32]

Unplanned additional intervention

$[21,22,24-27,29,30,32,33]$

Other complications

Intestinal fistula $[21,25,26,28,29]$

Sepsis $[23,25,26,31]$

Necrosis $[23,25]$

Thromboembolic $[30,31]$

Pulmonary [30, 31]

1. Overall hospital-stay
Statistical method, 95\%C,

$P$ value

$\mathrm{I}^{2}(\%)$ patients

$\mathrm{CM}$

13

$817 \quad 709$

WMD $=-1.29,95 \% \mathrm{Cl}[-2.42$, 93

$-0.16], P=0.03<0.05$

$224125 \mathrm{SMD}=0.66,95 \% \mathrm{Cl}[0.42$,

55

$0.91], \mathrm{P}<0.00001$

$224104 \mathrm{SMD}=0.26,95 \% \mathrm{Cl}[-0.13$,

$0.64], P<0.00001$

54

$\mathrm{OR}=1.65,95 \% \mathrm{Cl}[0.94$,

3.84], $P=0.1>0.05$

5

$171 \quad 105$

$298 \quad 195$

$\mathrm{OR}=15.83,95 \% \mathrm{Cl}[8.31$,

30.14], $\mathrm{P}=0.1>0.05$

0

$754625 \mathrm{OR}=2.733,95 \% \mathrm{Cl}[1.243$,

57

6.012], $\mathrm{P}=0.01<0.05$

$164222 \mathrm{OR}=2.41,95 \% \mathrm{Cl}[1.08$,

5.38], $P=0.03<0.05$

$713618 \mathrm{OR}=0.9,95 \% \mathrm{Cl}[0.54$,

1.47], $P=0.66>0.05$

$388 \quad 392 \quad \mathrm{OR}=4.14,95 \% \mathrm{Cl}[2.21$,
$7.75], \mathrm{P}<0.00001$

$\begin{array}{lll}388 & 392 & \mathrm{OR}=4.14,95 \% \mathrm{Cl}[2.21, \\ & 7.75], \mathrm{P}<0.00001\end{array}$

0

$\begin{array}{lll}344501 & \begin{array}{l}\mathrm{OR}=0.18,95 \% \mathrm{Cl}[0.11, \\ 0.30], \mathrm{P}<0.00001\end{array}\end{array}$

$\begin{array}{lll}344501 & \mathrm{OR}=0.18,95 \% \mathrm{Cl}[ \\ & 0.30], \mathrm{P}<0.00001\end{array}$

2


A total of 13 studies $^{20-26,28-33}$ reported the overall hospital-stay (Fig. 2. A), Heterogeneity existed in these studies $\left(P<0.05 ; I^{2}>50 \%\right)$, Egger test $P=0.951>0.1$, with no obvious publication bias. The effective amount of SMD in the random effect model did not change significantly before and after the metatrim method $\left(\mathrm{SMD}_{1}=-0.580,95 \% \mathrm{Cl}[-0.696,-0.465]\right),\left(\mathrm{SMD}_{2}=-0.735,95 \% \mathrm{Cl}[-1.338,-0.132]\right)$, the results were robust. The aggregate analysis showed that the length of stay of patients treated with surgery was about 1 day less than that of conservative treatment, and the difference was statistically significant $(\mathrm{WMD}=-1.29,95 \% \mathrm{Cl}[-2.42,-0.16], \mathrm{P}=0.03<0.05)$.

\section{Abdominal Abscess}

There were 11 studies ${ }^{20,22,23,26-32}$ reported the occurrence of abdominal abscess (Fig. 2. B), of which Brown ${ }^{25}$ classified the patients with diffuse peritonitis as abdominal abscess in the study, which did not meet the requirements of this study and was not included in the meta-analysis. The remaining 10 studies showed homogeneity $\left(P>0.05 ;\left.\right|^{2}<50 \%\right)$, Combined with the statistical amount $O R$, the results showed that the incidence of abdominal abscess was lower in surgical treatment than in conservative treatment, but the difference was not statistically significant $(\mathrm{OR}=0.9,95 \% \mathrm{Cl}[0.54,1.47], \mathrm{P}=0.66>0.05)$.

\section{Unplanned Additional Intervention}

A total of 10 studies 21,22,24-27,29,30,32,33 reported the occurrence of unplanned interventions during treatment in each group (Fig. 2. C), including conservative treatment failure, recurrent appendicitis, postoperative intestinal fistula, etc. With no significant heterogeneity among the studies $(P>0.05$; $\left.1^{2}<50 \%\right)$. The results showed that the incidence of unplanned additional interventions in 10 was significantly lower than $\mathrm{CM}$, and the difference was statistically significant $(\mathrm{OR}=0.18,95 \% \mathrm{Cl}[0.11,0.30]$, $P<0.00001)$.

\section{Wound infection}

A total of 12 studies were included in the incision infection (Fig. 3. D), among which there were 3 RCTS $^{20,21,23}$, and 9 retrospective studies ${ }^{24-32}$. The summarized results showed that patients in the CM group had a lower incidence of incision infection than those in the 10 group $(O R=2.733,95 \% \mathrm{Cl}[1.243$, $6.012], P=0.01<0.05)$. The studies were heterogeneous. $\left.(P<0.05), I^{2}>50 \%\right)$. With wound infection as indicators, Egger method was used to indicate the existence of publication bias $(P=0.001<0.1)$, and $P=$ $0.464>0.05$ after the use of metatrim method, suggesting the possibility of publication bias and the meta- analysis results of wound infection were not robust. Further analysis showed that in the four studies, percutaneous drainage was performed as required in the CM group (386 participants in the four studies $\left.^{25-27,30}\right)$. Compared with the 10 group, the difference was statistically significant $(O R=2.41,95 \% \mathrm{Cl}$ $[1.08,5.38], P=0.03<0.05)$. No heterogeneity was found among the studies $\left(P>0.05 ; I^{2}=0 \%\right)$ (Fig. 3.E).

\section{Post-operate Stay}


Four studies $26,28,32,33$ reported the length of postoperative stay (Fig. 4. F), with inter-study heterogeneity $\left(P<0.05 ; I^{2}>50 \%\right)$, and the Egger method was used to analyze the postoperative hospitalization time, and no significant publication bias was found $(P=0.859>0.1)$. Meta-analysis results showed that the postoperative hospitalization time of patients undergoing surgical treatment was longer than that after interval operate, and the difference was statistically significant (SMD $=0.66,95 \% \mathrm{Cl}$ $[0.42,0.91], \mathrm{P}<0.00001)$.

\section{Intestinal Obstruction}

Six studies ${ }^{25,26,29-32}$ reported the presence of intestinal obstruction in the surgery group and the conservative group (Fig. 4. G), and each study showed homogeneity $\left(P>0.05 ; I^{2}=0 \%\right)$. The results showed that the incidence of intestinal obstruction was higher in surgical treatment than in conservative treatment $(\mathrm{OR}=4.14,95 \% \mathrm{Cl}[2.21,7.75], \mathrm{P}<0.00001)$.

\section{Post-operate complication}

In the analysis of postoperative complications (Fig. 4. H), there were 5 studies $21,27,29,31,32$ included. No significant heterogeneity was found among the studies $\left(P>0.05,1^{2}<50 \%\right)$, The result showed that compared with conservative treatment, postoperative complications were more common in immediate appendectomy $(\mathrm{OR}=15.83,95 \%$ ci $[8.31,30.14], \mathrm{P}=0.1>0.05)$.

\section{Other Outcomes}

The analysis results of operate time $e^{27,28,32,33}$, overall complications ${ }^{28,30}$, intestinal fistula $21,25,26,28,29$, sepsis $^{23,25,26,31}$, necrosis ${ }^{23,25}$, DVT $^{30,31}$, pulmonary infection ${ }^{30,31}$ are shown in Table 2.

\section{Discussion}

We've found that the total time of admission decrease by about 1 day compared with conservative treatment. Despite the high heterogeneity, the outcome of the event was not reversed after the estimation by the metatrim method, indicating the robustness of this meta-analysis. At the same time, the incidence of unplanned additional intervention in patients undergoing emergency surgery is lower than that of conservative treatment, which means that patients undergoing conservative treatment were more likely to have emergency surgery or repeated admission due to failure of conservative treatment, recurrent appendicitis, abdominal abscess, and potential malignancy. This was the same as Mentula's ${ }^{22}$ conclusion.

However, patients undergoing 10 are more prone to complications such as wound infections and intestinal obstructions than conservative management patients. This may be related to the dirtier abdominal environment in the emergency surgery, and the conservative treatment group has a selective drain of the abdominal abscess to improve the environment. 
Notably, the meta-analysis of abdominal abscess shows that the incidence of abdominal abscess is lower with surgery than with conservative treatment. Although there is no statistically significant difference between the two, the results indicated that surgical treatment is more effective than conservative treatment in emptying the pus. Unfortunately, due to the lack of rigorous RCT researches, and the variety of patients, it is difficult to accurately determine the merits of surgical versus percutaneous drainage for abdominal abscess.

To date, there is no standard treatment for complicated appendicitis with localized perforation, abscess, or mass formation. In some areas, 10 for complicated appendicitis remains the preferred treatment for many surgeons. In recent years, the evidence that conservative treatment is a superior way of the complicated appendicitis has been questioned ${ }^{26}$. Some patients with conservative treatment finally have worse symptoms and lead to more surgical treatment. Not only that, the patient has to show a response for this anti-infective treatment to continue. These patients with the conservative management failure are eventually excluded from the analysis, this situation may cause data analysis more inclined to nonsurgical treatment.

As the follow-up of patients after discharge became more detailed, opponents of the strategy raised some issues caused by conservative treatment, such as recurrent appendicitis, missed potential malignancies, and unconsolidated appendicitis progressing to appendiceal mass. This study clearly explained that conservative treatment caused more additional operations to patients through the summary of studies in recent 20 years. At the same time, through statistical reasoning, this meta-analysis proves that surgical patients have shorter hospital stay.

Longer hospital stays, more antibiotic treatment and more unplanned treatments often result in higher costs for some patients. Recurrent appendicitis and potential tumors often mean multiple imaging and laboratory tests. It not only increases the burden of patients, but also causes a large occupation of medical resources. Repeated admissions also tend to increase the cost of inpatient management. While the complications of emergency surgical treatment of complicated appendicitis often occur at the first admission, and even some minor complications such as wound infection can be treated by lower-level medical institutions. In this respect, surgical treatment of complicated appendicitis is obviously better than conservative treatment.

The results of this study should be interpreted in light of the limitations of the study. Most studies did not report a clear intravenous antibiotic use time, so it cannot to summary the results evaluation. There are differences of low age of children's organ development, therefore biggish differences with anti-infection ability. This study only focuses on people over the age of 12 , does not apply to children. Although the heterogeneity of analysis results in some studies is low, it should be noted that the overall clinical status of patients in each group varies considerably. Even if there is statistical equivalence of some key results between the two groups, the utilization of medical resources and perioperative care are inconsistent. Unfortunately, although several studies have demonstrated the effectiveness of laparoscopic surgery in emergency surgical treatment of complicated appendicitis ${ }^{34,35}$, there is a lack of rigorous RCTS for 
laparoscopic versus conservative treatment. Few RCTs were included in this study, and some RCT studies for the outcome and descriptions of the process are not clear. A number of studies demonstrate the effectiveness of the complication of laparoscopy appendectomy ${ }^{22}$, but some retrospective studies put the main treatment as open appendectomy. We don't have enough RCT experiments compared laparoscopic and conservative management.

\section{Conclusions}

Immediately operation patients have shorter hospitalization time and less unplanned intervention than people who are in conservative management. It means that immediately operation can significantly reduce the readmission opportunity of patients with complicated appendicitis and lighten the burden of follow-up and medical resource consumption. In the future, randomized controlled trials involving more laparoscopic surgery versus conservative treatment will be able to better demonstrate the effectiveness of 10 and contribute to the establishment of appropriate methods for the treatment of complicated appendicitis.

\section{Abbreviations}

10

immediately operation;

$\mathrm{CM}$

conservative management;

IAA

interval appendectomy;

RS

retrospective study;

RCT

randomized controlled trial

WMD

Weighted Mean Difference

SMD

Standardized Mean Difference

\section{Declarations}

\section{Ethics approval and consent to participate}

Not applicable

\section{Consent for publication}

Not applicable 
Availability of data and materials

All data in this article are derived from published articles, and the data generated or analysed during this study are included in this article.

\section{Competing interests}

The authors declare that they have no competing interests.

\section{Funding}

All financial support in this study came from corresponding author sponsorship

\section{Authors' contributions}

Each author is responsible for the design of the study, the analysis of the data and the drafting and revision of the article, and ensure that questions related to the accuracy or integrity of any part of the work

The Corresponding authors Peng Gao ensure that all listed authors have approved the manuscript before submission, including the names and order of authors, make it certain that no author on earlier versions have been removed or new authors added, and all data comply with the transparency and reproducibility standards of both the field and journal.

\section{Acknowledgements}

Thanks to Lelong Qu and Bailing Zhang for their help on English writing. And Zhenlu Li give the help of data-gathering approach.

\section{Authors' information}

The author Chi Zhang is a graduate student of the affiliated hospital of Qingdao university, who is engaged in emergency surgery. He has come into contact with many patients with acute appendicitis in his work, and has great interest in the treatment of acute appendicitis.

\section{References}

1 Tannoury, J. Treatment options of inflammatory appendiceal masses in adults. World $\mathrm{J}$. Gastroenterol. 19, 3942, doi:10.3748/wjg.v19.i25.3942 (2013).

2 Hansson, L. E., Laurell, H. \& Gunnarsson, U. Impact of time in the development of acute appendicitis. Dig Surg 25, 394-399, doi:10.1159/000180451 (2008).

3 Ahmed, I., Deakin, D. \& Parsons, S. L. Appendix mass: do we know how to treat it? Ann R Coll Surg Eng/87, 191-195, doi:10.1308/1478708051649 (2005). 
4 Sippola, S. et al. Quality of Life and Patient Satisfaction at 7-Year Follow-up of Antibiotic Therapy vs Appendectomy for Uncomplicated Acute Appendicitis: A Secondary Analysis of a Randomized Clinical Trial. JAMA Surg, doi:10.1001/jamasurg.2019.6028 (2020).

5 Prechal, D., Post, S., Pechlivanidou, I. \& Ronellenfitsch, U. Feasibility, acceptance, safety, and effectiveness of antibiotic therapy as alternative treatment approach to appendectomy in uncomplicated acute appendicitis. Int J Colorectal Dis 34, 1839-1847, doi:10.1007/s00384-019-03392-1 (2019).

6 Darwazeh, G., Cunningham, S. C. \& Kowdley, G. C. A Systematic Review of Perforated Appendicitis and Phlegmon: Interval Appendectomy or Wait-and-See? Am Surg 82, 11-15 (2016).

7 Dong, Y., Tan, S., Fang, Y., Yu, W. \& Li, N. [Meta-analysis of laparoscopic surgery versus conservative treatment for appendiceal abscess]. Zhonghua Wei Chang Wai Ke Za Zhi 21, 1433-1438 (2018).

8 Gavriilidis, P., de'Angelis, N., Katsanos, K. \& Di Saverio, S. Acute Appendicectomy or Conservative Treatment for Complicated Appendicitis (Phlegmon or Abscess)? A Systematic Review by Updated Traditional and Cumulative Meta-Analysis. Journal of clinical medicine research 11, 56-64, doi:10.14740/jocmr3672 (2019).

9 Jeffrey, R. B., Jr., Federle, M. P. \& Tolentino, C. S. Periappendiceal inflammatory masses: CTdirected management and clinical outcome in 70 patients. Radiology 167, 13-16, doi:10.1148/radiology.167.1.3347712 (1988).

10 Bagi, P., Dueholm, S. \& Karstrup, S. Percutaneous drainage of appendiceal abscess. An alternative to conventional treatment. Diseases of the colon and rectum 30,532-535, doi:10.1007/bf02554784 (1987).

11 Olsen, J., Skovdal, J., Qvist, N. \& Bisgaard, T. Treatment of appendiceal mass-a qualitative systematic review. Dan Med J 61, A4881 (2014).

12 Higgins JPT, T. J., Chandler J, Cumpston M, Li T, Page MJ, Welch VA (editors). Cochrane Handbook for Systematic Reviews of Interventions version 6.0 (updated July 2019). Cochrane, 2019. Available from www.training.cochrane.org/handbook.

13 Stang, A. Critical evaluation of the Newcastle-Ottawa scale for the assessment of the quality of nonrandomized studies in meta-analyses. European journal of epidemiology 25, 603-605, doi:10.1007/s10654-010-9491-z (2010).

14 Kirby, C. P. \& Sparnon, A. L. Active observation of children with possible appendicitis does not increase morbidity. ANZ J Surg 71, 412-413, doi:10.1046/j.1440-1622.2001.02148.x (2001).

15 Xinwei, L. Observation of the clinical and pathological character of child acute appendicitis. CHINA MEDICAL HERALD 9, 174-175 (2012). 
16 Hozo, S. P., Djulbegovic, B. \& Hozo, I. Estimating the mean and variance from the median, range, and the size of a sample. BMC medical research methodology 5, doi:10.1186/1471-2288-5-13 (2005).

17 Luo, D., Wan, X., Liu, J. \& Tong, T. Optimally estimating the sample mean from the sample size, median, mid-range, and/or mid-quartile range. Statistical methods in medical research 27, 1785-1805, doi:10.1177/0962280216669183 (2018).

18 Wan, X., Wang, W., Liu, J. \& Tong, T. Estimating the sample mean and standard deviation from the sample size, median, range and/or interquartile range. $B M C$ medical research methodology 14,135 , doi:10.1186/1471-2288-14-135 (2014).

19 Duval, S. \& Tweedie, R. Trim and fill: A simple funnel-plot-based method of testing and adjusting for publication bias in meta-analysis. Biometrics 56, 455-463, doi:10.1111/j.0006-341x.2000.00455.x (2000).

20 Khan, S. A., Ali, M. \& Seerat, M. I. Efficacy of Early Exploration in Appendicular Mass. Pak. J. Med. Health Sci. 10, 781-783 (2016).

21 Kumar, S. \& Jain, S. Treatment of appendiceal mass: prospective, randomized clinical trial. Indian journal of gastroenterology : official journal of the Indian Society of Gastroenterology 23, 165-167 (2004).

22 Mentula, P., Sammalkorpi, H. \& Leppaniemi, A. Laparoscopic Surgery or Conservative Treatment for Appendiceal Abscess in Adults? A Randomized Controlled Trial. Ann Surg 262, 237-242, doi:10.1097/sla.0000000000001200 (2015).

23 Pathan, M. F. et al. COMPARATIVE STUDY OF IMMEDIATE SURGICAL INTERVENTION VERSUS CONSERVATIVE TREATMENT IN APPENDICULAR LUMP. Indo Am. J. Pharm. Sci. 5, 606-610, doi:10.5281/zenodo.1165099 (2018).

24 Aranda-Narvaez, J. M. et al. Conservative approach versus urgent appendectomy in surgical management of acute appendicitis with abscess or phlegmon. Revista espanola de enfermedades digestivas : organo oficial de la Sociedad Espanola de Patologia Digestiva 102, 648-652, doi:10.4321/s1130-01082010001100005 (2010).

25 Brown, C. V., Abrishami, M., Muller, M. \& Velmahos, G. C. Appendiceal abscess: immediate operation or percutaneous drainage? Am Surg 69, 829-832 (2003).

26 Deelder, J. D., Richir, M. C., Schoorl, T. \& Schreurs, W. H. How to treat an appendiceal inflammatory mass: operatively or nonoperatively? J Gastrointest Surg 18, 641-645, doi:10.1007/s11605-014-2460-1 (2014).

27 Demetrashvili, Z. et al. Comparison of treatment methods of appendiceal mass and abscess: A prospective Cohort Study. Ann Med Surg (Lond) 48, 48-52, doi:10.1016/j.amsu.2019.10.016 (2019). 
28 Liu, Z. F., Yu, J. C., Hsieh, H. F. \& Lin, C. H. Perforated appendicitis: urgency or interval surgery? Zentralb/ Chir 132, 539-541, doi:10.1055/s-2007-981369 (2007).

29 Motie, M. R. et al. Is Interval Appendectomy Necessary for Appendicular Phlegmon? A Prospective Study. Indian J. Surg 80, 494-499, doi:10.1007/s12262-017-1644-9 (2018).

30 Oliak, D. et al. Initial nonoperative management for periappendiceal abscess. Diseases of the colon and rectum 44, 936-941, doi:10.1007/bf02235479 (2001).

31 Shekarriz, S. et al. Comparison of conservative versus surgical therapy for acute appendicitis with abscess in five German hospitals. Int J Colorectal Dis 34, 649-655, doi:10.1007/s00384-019-03238-w (2019).

32 Watanabe, R. et al. Superior outcomes (but at higher costs) of non-operative management with interval appendectomy over immediate surgery in appendicitis with abscess: Results from a large adult population cohort. Asian J Endosc Surg, doi:10.1111/ases.12726 (2019).

33 Young, K. A. et al. Outcomes of complicated appendicitis: Is conservative management as smooth as it seems? Am J Surg 215, 586-592, doi:10.1016/j.amjsurg.2017.10.032 (2018).

34 Thomson, J.-E. et al. Laparoscopic versus open surgery for complicated appendicitis: a randomized controlled trial to prove safety. Surgical Endoscopy 29, 2027-2032, doi:10.1007/s00464-0143906-y (2015).

35 Dimitriou, I., Reckmann, B., Nephuth, O. \& Betzler, M. Single institution's experience in laparoscopic appendectomy as a suitable therapy for complicated appendicitis. Langenbecks Arch Surg 398, 147-152, doi:10.1007/s00423-012-1035-4 (2013).

\section{Figures}




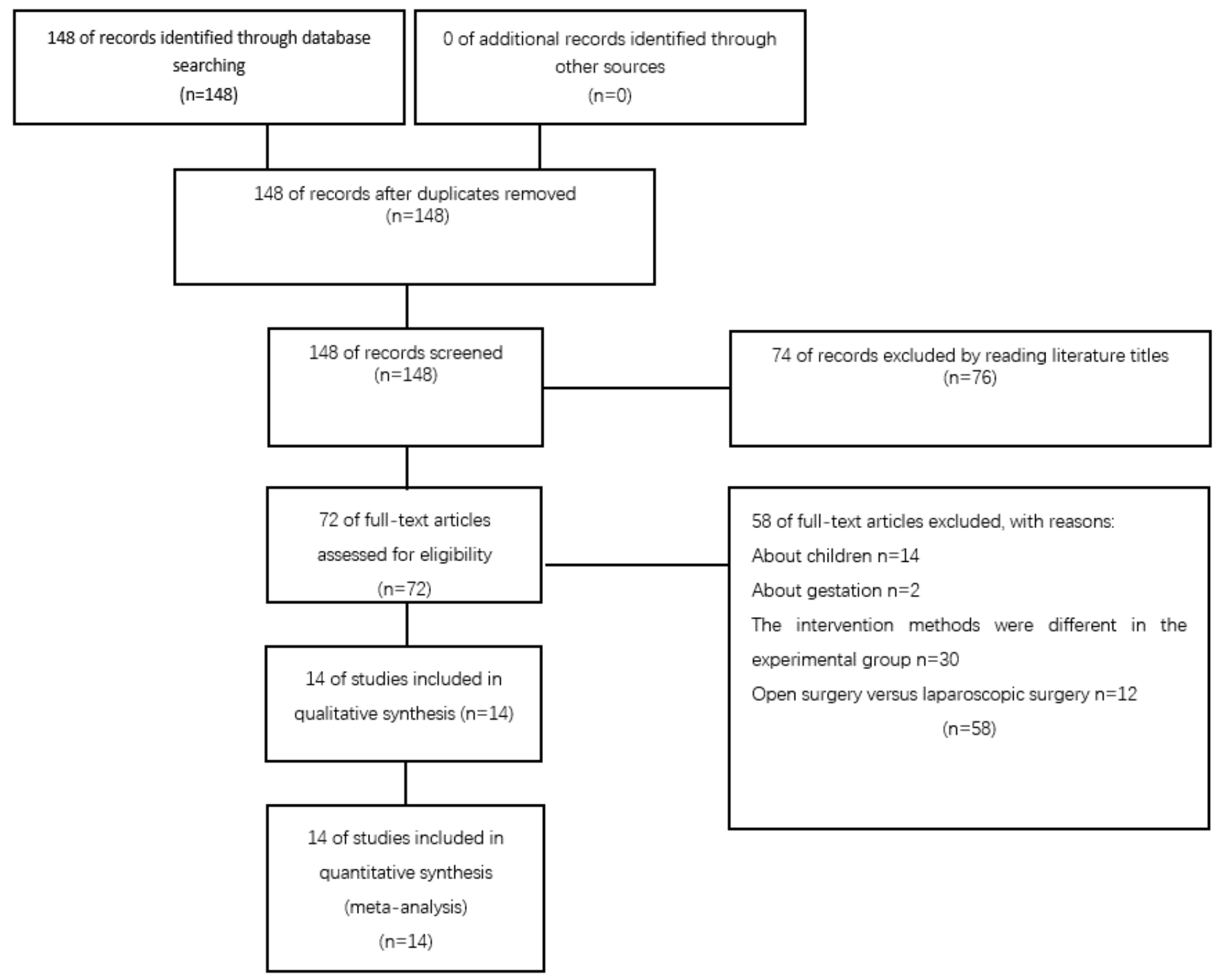

Figure 1

Figure 1. Study flow diagram 


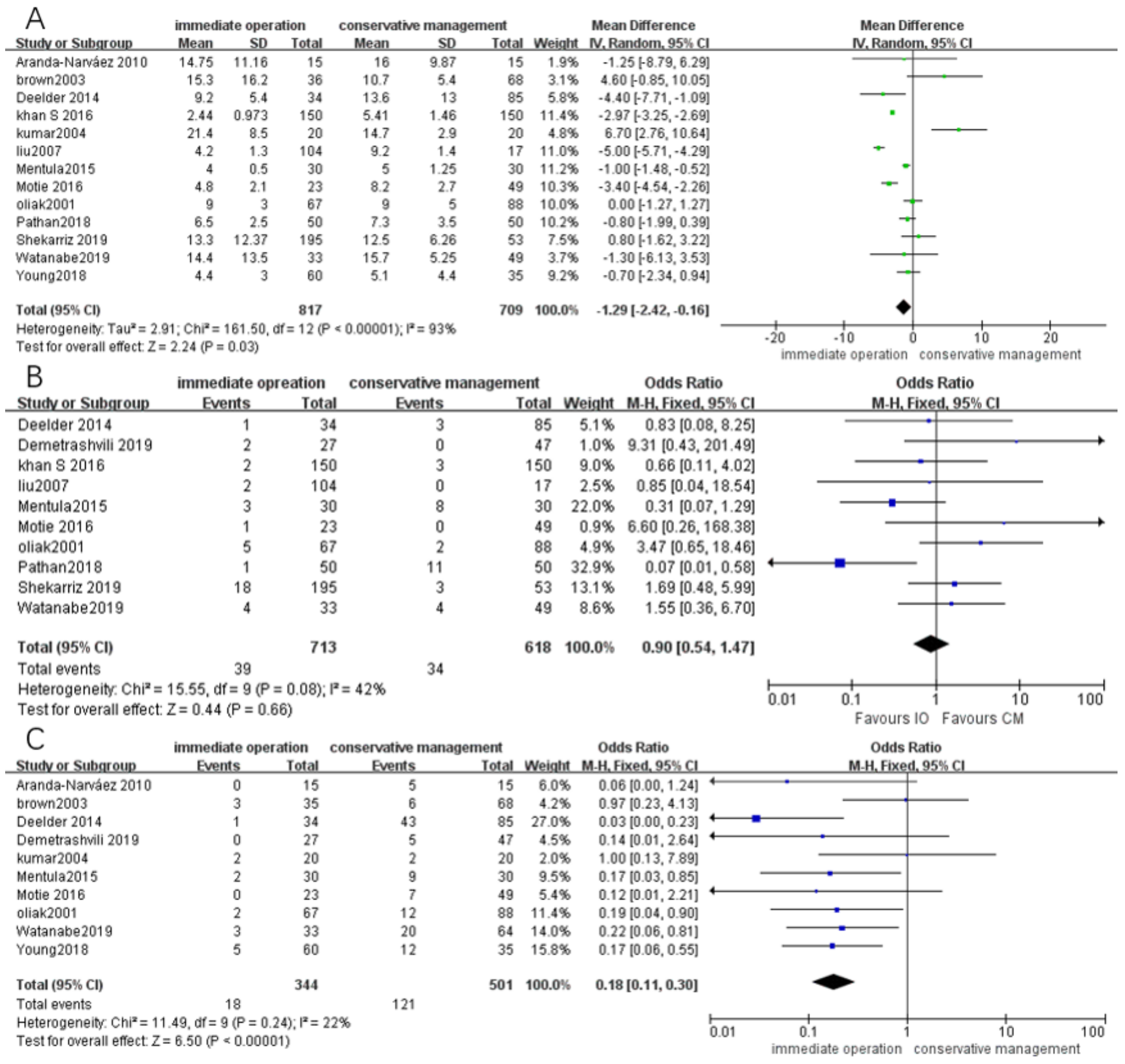

\section{Figure 2}

Figure 2: A. Overall hospital stay. B. Abdominal abscess. C. Unplanned additional intervention 


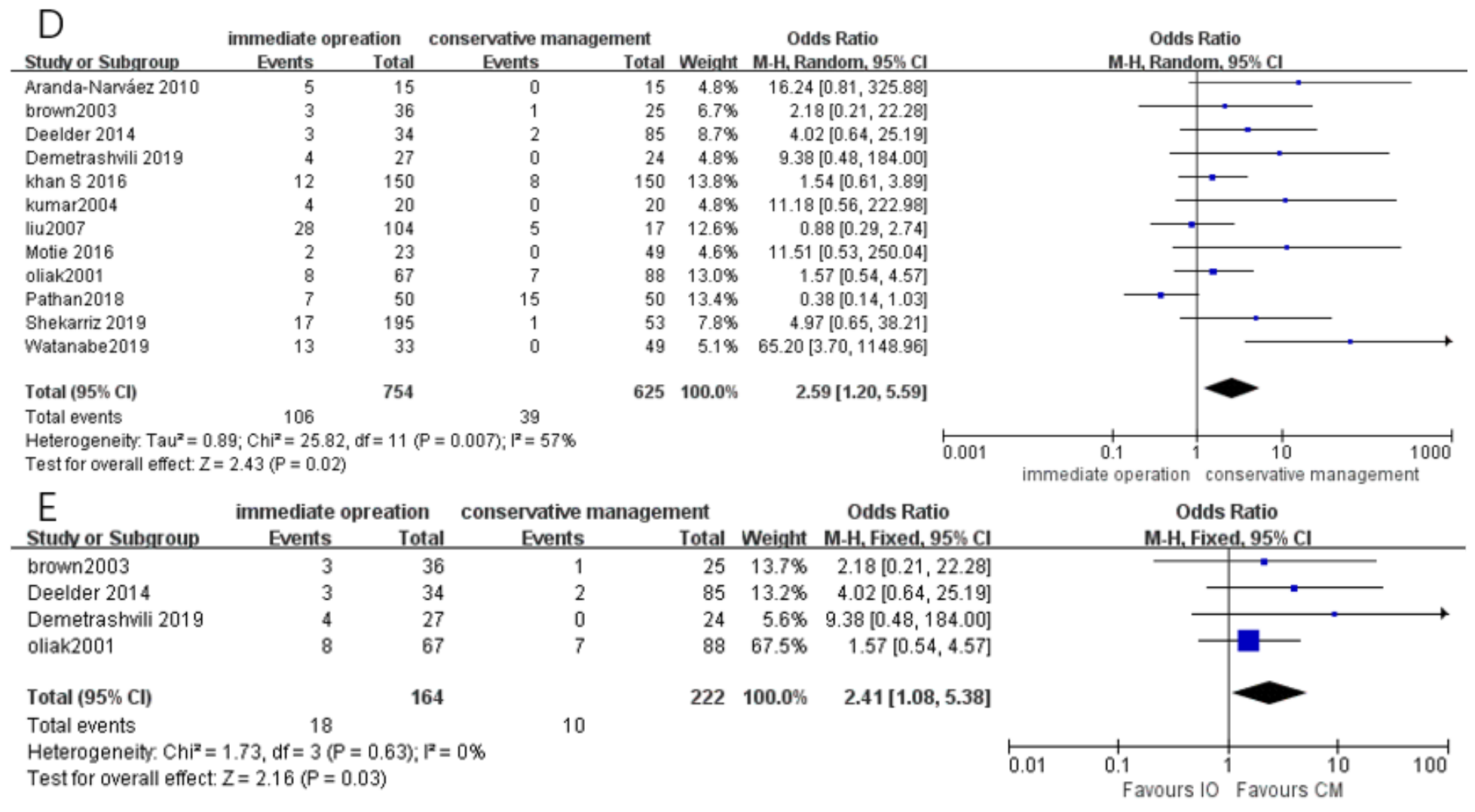

\section{Figure 3}

Figure 3: D. Wound infection. E. Wound infection in percutaneous drainage patients 
F

\begin{tabular}{lrrr} 
Studv or Subgroup & Mean & SD & Total \\
\hline Deelder 2014 & 10.4 & 3.1 & 27 \\
liu2007 & 3.6 & 1.2 & 104 \\
Watanabe2019 & 14.4 & 13.5 & 33 \\
Young2018 & 4.4 & 3.4 & 60
\end{tabular}

Total (95\% Cl)

224

Heterogeneity. $\mathrm{Ch}^{2}=6.64, \mathrm{df}=3(\mathrm{P}=0.08) ; \mathrm{I}^{2}=55 \%$

Test for overall effect: $Z=5.33$ ( $P<0.00001)$
Std. Mean Difference IV. Fixed, $95 \% \mathrm{Cl}$

conservative management Mean SD Total Weight

$\begin{array}{llll}8.1 & 2.9 & 24 & 18.2 \%\end{array}$

$\begin{array}{llll}3.2 & 1.4 & 17 & 22.4 \%\end{array}$

$\begin{array}{llll}4.3 & 2.25 & 49 & 26.1 \%\end{array}$

$\begin{array}{llll}2.7 & 4.1 & 35 & 33.3 \%\end{array}$

$125100.0 \%$

$0.32[-0.19,0.84]$

$1.15[0.67,1.62]$

$0.46[0.04,0.88]$

$0.66[0.42,0.91]$
$0.75[0.18,1.32]$

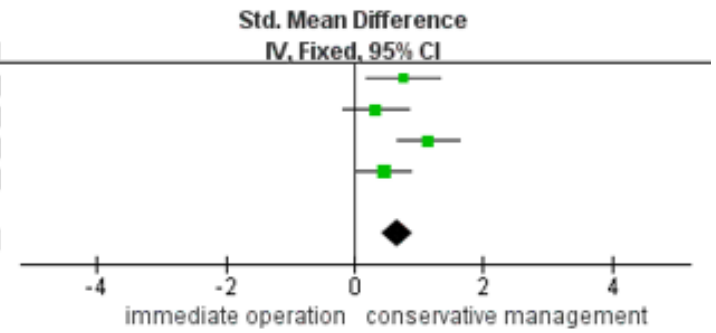

G

Study or Subgroup

immediate opreation

conservative management Events Events brown2003

Deelder 2014

Motie 2016

oliak2001

Shekarriz 2019

Watanabe2019

Total $(95 \% \mathrm{Cl})$

Total events

Heterogeneity: $\mathrm{Chi}^{2}=2.87, \mathrm{df}=5(P=0.72) ; \mathrm{I}^{2}=0 \%$

Test for overall effect: $Z=4.45$ ( $P<0.00001)$

\section{$\mathrm{H}$}

Study or Subgroup

immediate opreation conservative management

Demetrashvili 2019

kumar2004

Motie 2016

Shekarriz 2019

Watanabe 2019

Total $(95 \% \mathrm{Cl})$

Total events

Heterogeneity. $\mathrm{Chi}^{2}=6.07, \mathrm{df}=4(\mathrm{P}=0.19) ; \mathrm{I}^{2}=34 \%$

Test for overall effect $Z=8.40(P<0.00001)$

27
20
23
195
33
298
$1^{2}=34 \%$

Total Weight M-H. Fixed 95\% CI

$\begin{array}{rrr}68 \text { tal } & \text { Weight } & \text { M-H, Fixed, } 95 \% \mathrm{Cl} \\ 68 & 2.9 \% & 5.79[0.23,145.78]\end{array}$

$85 \quad 9.6 \% \quad 1.26[0.11,14.34]$

$49 \quad 2.6 \% \quad 6.60[0.26,168.38]$

$\begin{array}{lll}88 & 31.8 \% & 2.91[0.95,8.97]\end{array}$

$53 \quad 47.8 \% \quad 4.06[1.54,10.73]$

$49 \quad 5.3 \% \quad 15.36[1.82,129.81]$

$392100.0 \%$

13 Events

$\begin{array}{ll}0 & \text { To } \\ 0 & \\ 0 & \\ 9 & \\ 1 & \end{array}$

10

$195100.0 \% \quad 15.83[8.31,30.14]$

al Weight

$24 \quad 6.8 \% \quad 14.81[0.79,278.59]$

$20 \quad 5.8 \% \quad 18.38[0.96,352.57]$

$\begin{array}{lll}49 & 4.2 \% & 29.43[1.55,558.92]\end{array}$

$5380.0 \% \quad 9.56[4.40,20.76]$

$49 \quad 3.3 \% \quad 150.00[17.75,1267.70]$

immediate operation consen
Odds Ratio

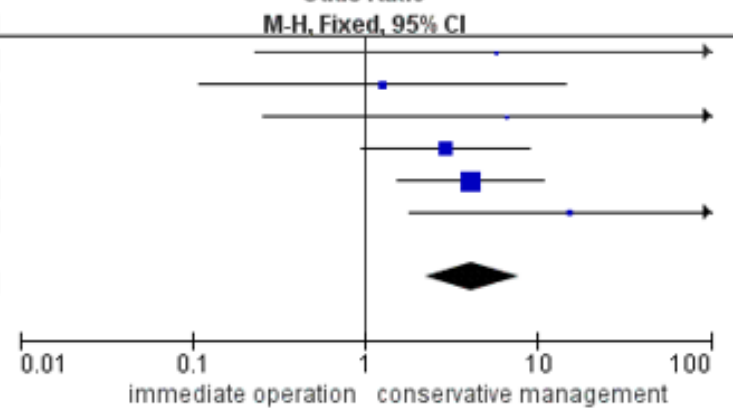

immediate operation conservative management

Odds Ratio

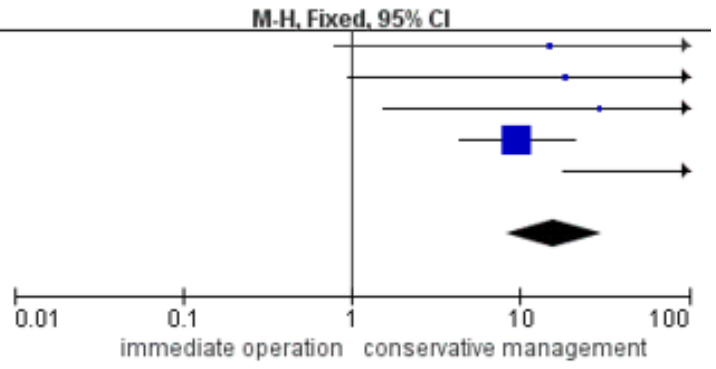

\section{Figure 4}

Figure 4: F. Post-operate stay, G. Intestinal obstruction. H. Post-operate complication 